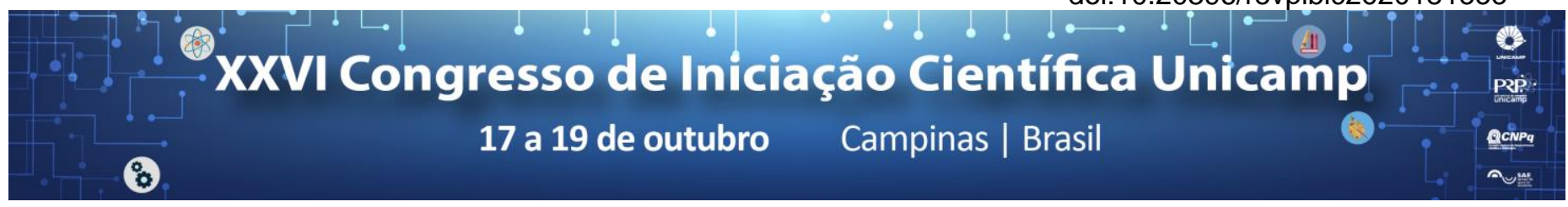

\title{
Obstáculos ao desenvolvimento sustentável em regiões de expansão canavieira.
}

\author{
Victor A. A. Pinto, Jose Maria F. J. da Silveira
}

\begin{abstract}
Resumo
Frente à grande influência não só econômica, mas também social e ambiental da cana-de-açúcar no Brasil que veio a aumentar com a expansão recente das plantações da cana nos últimos anos, este trabalho pretende relacionar a percepçãoo dos stakeholders locais áreas dos impactos da expansão recente obtidos a partir da cooperação com outra pesquisa em andamento com um estudo das redes de influências do processo de formação das opiniões dos formuladores das políticas públicas, tendo vista os potenciais influenciadores como ONGs,a academia e órgãos governamentais por exemplo. A pesquisa foi realizada a título de Projeto de Iniciação Científica na Universidade Estadual de Campinas, Instituto de Economia, financiado através de recursos do Conselho Nacional de Desenvolvimento Científico e Tecnológico (CNPq), via Programa Institucional de Bolsas de Iniciação Científica e Tecnológica da Unicamp (PIBIC).
\end{abstract}

\section{Palavras-chave:}

Políticas públicas, bio-fuels, cana-de-açúcar.

\section{Introdução}

O setor sucro-alcooleiro no Brasil passou por grandes mudanças nos últimos 20 anos, tendo as políticas públicas grande participação nesse processo como visto em DE OLIVEIRA, 2017. Essa expansão a partir dos anos 2000 provocou alterações estruturais importantes no setor elencando novas indagações que antes não pertenciam ao cotidiano como preocupações importantes dos stakeholders do complexo agroindustrial. Os investimentos deixaram seus centros tradicionais e passaram a "transbordar" à regiões dos estados de Minas Gerais, São Paulo, Goiás, Mato Grosso do Sul e Paraná (Marques Postal, 2014).

Tendo em vista as visões opostas de diferentes formadores de opinião como ONGs, órgãos públicos e instituições acadêmicas que tem influência na formação das opinões dos policy-makers cabe a este trabalho o objetivo de relacionar a percepão dos impactos da expansão recente da cana com o processo da formação de tais opiniões.

\section{Resultados e Discussão}

Durante a pesquisa alguns resultados variados capazes de sucitar relevante discussão foram atingidos: Para identificar o nível de relevância da opinião internacional das ONGs sobre biocombustíveis nas políticas públicas foram revisados diversos documentos emitidos por organizações internacionais como ONU, World Bank, , entre outros, e não foi encontrada nenhuma referência direta a qualquer trabalho ou artigo de qualquer ONG, levantando a discussão de como relacionar a opinião final dos formuladores das políticas públicas com os argumentos apresentados pelas ONGs.

Também foram analisados textos acadêmicos sobre a relevância das políticas públicas no desenvolvimento de setores de inovação, principalmente nas tecnologias ligadas à cana-de-açúcar. Demonstrouse alta correlação entre o desenvolvimento do setor e a promoção de políticas públicas a ele relacionadas. Para aprofundar tal análise, desenvolveu-se uma metodogia de pesquisa em que o intuito era entrevistar alguns indivíduos de destaque do setor sucro-alcooleiro e procurar averiguar qual seria o processo pelo qual a formação de opinião e conhecimento desses indivíduos passa. O que levanta a discussão da numerosa presença de artigos acadêmicos que procuram identificar o impacto das políticas públicas nos setores em que atuam, enquanto o processo de formação das opiniões que moldam essas políticas permanece pouco abordado.

Ao mesmo tempo, durante a iniciação científica, auxiliou-se outra pesquisa em andamento que procurava identificar a percepção dos impactos do avanço da canade-açúcar nos últimos dez anos dos stakeholders locais. Para tanto foram realizadas entrevistas com tais stakeholders, com questionamentos feitos, dos quais a análise lograram não apenas resultatos quantitativos que expressam o posicionamento dos stakeholders quanto ao avanço da cana, mas também dados qualitativos sobre cada questionamento feito, ou seja, foi gravado o porquê de cada indivíduo se posicionar de tal forma.

Entretanto, percebe-se clara divergência entre os avanços identificados pela opinião acadêmica e a percepção principalmente dos indivíduos identificados pela pesquisa como mais críticos quanto aos mesmos avanços.

\section{Conclusões}

Averigou-se que a influência dos atores ONGs, academia e órgãos governamentais tem baixa relação e comunicação umas com as outras, ao mesmo tempo que a grande influência das políticas públicas formuladas quanto ao etanol principalmente foram notadas pelos stakeholders locais. Destaca-se principalmente a divergência da perpecção entre a opinião das instituições acadêmicas com os indivíduos mais críticos e com a opinião dos demais órgãos averiguados.

DE OLIVEIRA, A. A. Mudanças e permanências no sistema setorial de inovação da cana-de-açúcar: o caso do etanol celulósico. Tese de Doutorado apresentada ao Instituto de Geociências para obtenção do título de Doutor em Política Científica e Tecnológica. Campinas: Unicamp, 2017.

MARQUES POSTAL, A. Acesso à cana-de-açúcar na Expansão sucroenergética Brasileira pós 2000: o caso de Goiás. Dissertação de Mestrado em Desenvolvimento Econômico. Instituto de Economia. UNICAMP, Campinas, 2014. 